\title{
LA PUERTA NUEVA O DE SAN FERNANDO
}

\author{
por Jose MANUEl SuAREZ GaRMENDia
}

\begin{abstract}
Presentamos un estudio sobre la ubicación exacta de una puerta de la ciudad de Sevilla, concretamente de la Puerta Nueva o de San Fernando realizada hacia 1760 para servicio de la Fábrica de Tabacos y de la ciudad. El estudio parte del hallazgo de una fotografía de la puerta tomada hacia 1868, poco antes del derribo de la misma. También se muestra un plano del sector en el que se aprecia el trazado de la antigua muralla en su discurrir por la calle de San Fernando.
\end{abstract}

This article deals with the exact location of one of the gates of the city of Seville, La Puerta Nueva or Puerta de San Fernando, constructed about 1760 to serve the Tobacco Factory and the city. The study is bsed on the discovery of a photograph of the gate taken around 1868 , shortly before it was demolished. Also shown is a plan of the sector in which the line of the old wall which passed through Calle San Fernando can be seen.

La feliz circunstancia del hallazgo de una fotografía de la Puerta de San Fernando nos ha movido a iniciar alguna investigación sobre la misma. Por otra parte nos llamó la atención cierta discordancia entre la imagen que nos presentaba la fotografía con la que nosotros nos habíamos creado a través de los testimonios iconográficos de pinturas, relatos y grabados del siglo pasado.

La fotografía, ésta en concreto, tiene un gran valor lo mismo que todo aquello que nos ayude a recuperar, de una manera o de otra, la iconografía de nuestra ciudad en cualquier momento y época. Toda referencia es buena sobre todo si es novedosa y fiable y evidentemente la fotografía de alguna manera es un testigo presencial del pasado pero además con un valor añadido: el de la objetividad. No cabe duda que es la fuente documental con mayor poder referencial. Muchos teóricos la asocian a la memoria por su capacidad de retener y de evocar y efectivamente nosotros ahora queremos usarla como un registro fiel de la realidad a pesar de su particular convencionalismo.

Técnicamente se trata de una copia a la albúmina sobre un soporte de papel de 200 gr. con unas dimensiones de $332 \times 253 \mathrm{~mm}$. Con toda seguridad fue positivada por contacto, como era normal por la fecha de su realización. El aspecto general que presenta la imagen es un tanto desvaido, con tonos ama- 
rronados y poco intensos sin que esto obedezca a un virado, sino más bien a una decoloración. En general se aprecia una falta de tonos medios debido al carácter ortocromático de la emulsión, pero en cambio tiene una buena respuesta al detalle y un grano muy fino. La lentitud del material sensible se evidencia también en la borrosidad o desenfoque de la persona que se apoya junto al vano de la puerta, así como en una huella borrosa en la calle de San Fernando, visible a través del arco, producida seguramente por el movimiento pasante de un carro o de algún animal. Todo esto se hace aún más patente si tenemos en cuenta que el día de la toma es muy luminoso, por la mañana y a una hora cercana al medio día como nos lo señalan la nitidez y la longitud de las sombras.

En cuanto a la cronología de la toma, unicamente podemos señalar una fecha «ante quen» ya que la puerta fue derribada en septiembre de 1868 tras los acontecimientos revolucionarios. Pocos elementos connotativos tenemos para aproximarnos más, aunque en nuestra opinión ya se había derribado la Puerta de Jerez, lo cual sucedía en 1864.

A esta conclusión hemos llegado después de identificar las casas que aparecen al final de la calle de San Fernando, a la izuqierda, a través del arco. Las casas están en obras como se aprecia por los andamiajes que cubren sus fachadas y sabemos que se edificaron a raiz de la nueva alineación de la Plaza de Maese Rodrigo, tras el derribo de la Puerta de Jerez ${ }^{1}$. Esto nos va a permitir ser algo más precisos. Teniendo en cuenta los retrasos que sufren los trámites de aprobación, permisos de obras, etc... y el hecho de que las fachadas estén ya levantadas, creemos que la fotografía está tomada el mismo año que se derribó la puerta, o sea el año 1868. Incluso suponemos que la fotografía se tomó con el ánimo de perpetuar documentalmente un trozo de Sevilla que inevitablemente se iba a destruir.

La Puerta de San Fernando estaba situada al final de la calle del mismo nombre comunicando la ciudad con el Prado de San Sebastián. Exactamente una de las torres ocupaba el terreno contiguo al actual restaurante Oriza y la torre frontera estaba hacia la medianía de la calle, en línea con el final de la actual Capilla de la Universidad. Se levanta en torno a 1760 para dar servicio a la ciudad y Fábrica de Tabacos a través de la que en principio se llamó calle Real de San Carlos y luego de San Fernando ${ }^{2}$, que también se realiza en la misma fecha.

La toma fotográfica se hizo extramuros de la ciudad, a la altura del recién cubierto vado del arroyo Tagarete que a pocos metros de la capilla se sumergía en una bóveda y atravesaba el patio de la Fama.

1. Archivo Administrativo Municipal de Sevilla. Se aprueba ésta alineación en el cabildo de 23 de enero de 1866. Posteriormente toda esta manzana será derribada para formar la actual plaza de la Puerta de Jerez que va a permitir que se quede en primera línea el solar donde en 1893 se va a labrar la casa Guardiola.

2. Montoto, S. «Las calles de Sevilla». Sevilla, 1940, pág. 399. 
La fotografía nos muestra la Puerta Nueva o de San Fernando, que así se llamó, entre dos torreones. El autor, con muy buen criterio, la tomó ligeramente desplazado del eje de la puerta, para de esta forma mostrarnos una orilla de la calle de San Fernando donde estaban ubicadas las casas que también se realizaron en 1760 para alquilarlas a los empleados en beneficio del «erario público». De esta manera a través del ojo de la puerta nos aporta una información complementaria que desde otro punto de vista se hubiera perdido.

El aspecto de esta puerta de la ciudad siempre nos llamó la atención por su disposición con relación a las dos torres que la flanquean, aspecto este que se observa perfectamente en el grabado que se hizó en 1878 para ilustrar la obra de F. de Borja Palomo. Este grabado, realizado probablemente por To$\operatorname{var}^{3}$, es la única iconografía de la puerta que hasta ahora ha permitido conocer el aspecto de ella de forma precisa.

No obstante hay abundantes representaciones de la misma siempre a través del testimonio, subjetivo ciertamente, de algunos pintores y dibujantes del siglo pasado que tomaron vistas de la ciudad desde el Prado de San Sebastián, sobre todo porque desde aquí se podía mostrar mejor que desde ningún sitio el perfil de la Giralda que se erguía esbelta a través de la vegetación, incipiente aún, de la Huerta del Retiro. Entre éstos destacaríamos la visión que nos dejó Richar Ford, Domínguez Becquer, Guesdión, Guichot, Marti, Bartolomé Tovar, etc... De todos fue Tovar quién realizó los dibujos más exactos de la puerta para ilustrar, junto con otras doce láminas de las restantes puertas, el libro de «Las Riadas...». Estos son los grabados más utilizados, por los estudiosos del tema, desde que Sancho Corbacho los divulgara en su «Iconografía de Sevilla».

Cuando apareció la fotografía que venimos comentando, comprobamos con gran sorpresa, que Tovar realizó su dibujo de «La Fachada Exterior de la Puerta Nueva o de San Fernando» sirviéndose literalmente de ésta, lo cual se deduce fácilmente del examen comparativo de las dos imágenes. En ambas se aprecia la coincidencia exacta del ángulo o punto de vista, así como la distribución de las sombras y la extraña disposición de las torres. Este puede ser un ejemplo más que nos ilustra el uso que hicieron algunos pintores y dibujantes de la fotografía ${ }^{4}$. No obstante hay que añadir que si esto, que parece evidente, va en detrimento del aspecto artístico de la obra de Tovar, en cambio se nos muestra muy valioso en el aspecto documental para el análisis iconográfico de las puertas de la ciudad, ya que suponemos que para las ilustraciones de las restantes puertas hizo lo mismo y algunas de las cuales sólo las conocemos a través de su obra.

3. Sancho Corbacho, A. «Iconografía de Sevilla». Sevilla, 1975. Lám. 136. Un aspecto parcial, también fotográfico, nos lo ofrece Luís Montoto en «La calle de San Fernando y la Fábrica de Tabacos». Sevilla, 1919.

4. Stelzer, Otto. «Arte y fotografía; contactos, influencias y efectos». Gustavo Gili. Barcelona, 1981. 
La disposición de las torres respecto a la puerta es ciertamente atípica, aunque en la muralla sevillana no lo sea tanto sobre todo en aquéllas zonas donde se han hecho muchas reedificaciones como fue el caso del Patín de las Damas o en su vecina Puerta de la Barqueta. En la fotografía se aprecia que ambas torres están giradas 45 grados su posición normal presentando una gran convergencia en sus lados hacia el interior, cuando lo más lógico es que éstos fueran paralelos. Por otra parte, la distancia mínima entre ambas es de 8 metros aproximadamente lo que está fuera de toda lógica por su cercanía, sobre todo teniendo en cuenta que eso es lo que miden sus bases. Esto nos lleva a suponer que estas torres no eran de la cerca de la ciudad, al menos una de ellas.

Acudiendo a la representación topográfica más antigua de la ciudad, por ahora, esto es, el plano parcial de 1728, donde el ingeniero Ignacio Salas replantea la Fábrica de Tabacos ${ }^{5}$, observamos que en la esquina de lo que será Calle de San Fernando por el Prado no hay ninguna pareja de torres en estas circunstancias. Este detalle se muestra con más precisión en el proyecto del mismo ingeniero para la fábrica también de la misma fecha ${ }^{6}$.

Hasta 1758, en los planos del ingeniero Sebastián Van Der Borcht, no se ven con cierta claridad las dos torres que van a cobijar la puerta. El proyecto definitivo de las torres, la Puerta Nueva, la calle de nueva formación (llamada ahora de San Carlos) que se segrega de la Huerta de la Alcoba, así como las veintiuna casas que configuran uno de los lados de la calle Nueva..., se ven por primera vez en el plano de 1760 firmado por Van Der Borcht (Foto 5) ${ }^{7}$.

En segundo lugar obervamos que la planta de la puerta, del plano de 1760, no coincide con el alzado que nos presenta la fotografía, lo que también ocurre en los planos generales de la ciudad levantados por orden de los Asistentes Olavide en 1771 y Pedro López de Lerena en 1788.

Con respecto a la primera observación nuestra hipótesis es que el ingeniero Sebastián Van Der Brocht es el autor del replanteamiento de la calle de San Fernando y de las viviendas que se realizan frente a la fábrica. La muralla de la ciudad queda, parcialmente, cerrando el edificio y parte de ella, aproximadamente desde el frente de la puerta principal, se derriba para atirantarla y enlazarla con una torre de nueva construcción junto a las cocheras y capilla (Foto 5, letra $\mathrm{H}$ ). Esta torre se hizo en disposición simétrica a la otra de la cerca de la ciudad con objeto de albergar entre ambas la puerta y de esa manera aprovechar la antigua. En el plano de 1758, concretamente en lo señalado con la letra $\mathrm{V}$, ya se nos anuncia algo de esta modificación así como una rectificación en la muralla de la Huerta del Retiro.

5. Citados por Aguilar Piñal, F. en «Historia de Sevilla: el siglo XVIII». Sevilla, 1982. Nota n. ${ }^{\circ}-7$. Después reporucido en «Sevilla y el tabaco». Bonet Correa, A. en «La Fábrica de Tabacos de Sevilla, primer edificio de la Arquitectura Industrial en España». Sevilla, 1984, pág. 48.

6. Ibid. Bonet Correa, pág. 57.

7. Plano publicado por Falcón Márquez, T., «La Fábrica de Tabacos». Rev. Aparejadores n. ${ }^{\circ} 9$. Diciembre de 1982. 
Respecto a la segunda observación creemos que esa falta de coincidencia de la planta y el alzado de la puerta se debe a que el frente que nos presenta la fotografía, es decir, el hueco, los ordenes y el antepecho no se realizan, por lo menos, hasta la última década del siglo XVIII. Se ve claramente cómo el frente de la puerta está a paño con las aristas exteriores de las dos torres ${ }^{8}$. Esto se contradice con la planta representada en el plano de 1760. Lo mismo ocurre con los planos de la ciudad, ya citados, de 1771 y 1788 que representan la planta de la puerta del mismo modo.

La única explicación posible que encontramos es que esta puerta se realizó en dos fases. Primero la parte que mira a la ciudad, construida por Van Der Brocht, cuya apertura se realiza el año 1760 . Después, en su momento posterior al año 1788, fecha del plano de López de Lerena, se construyó la parte que mira al Prado de San Sebastián y que es la que vemos en la fotogrfía. Esta interrupción en las obras de la fábrica no sabemos si fue debida a la destitución de Van Der Borcht, que sucedió en 1766, pero queremos hacer notar que el foso quedó sin terminar también en la zona Sur, a pesar de la inscripción en el puente del Rastrillo que lo da por concluido en 1770. Los planos de la ciudad citados nos dicen repetidamente que no fue así lo que nos hace suponer que esta inscripción responde al tramo de poniente únicamente.

Desde aquí, por no tener mejores argumentos, apuntamos la posibilidad de que este frente de la puerta se realizó a finales del siglo XVIII o principios del XIX. Incluso nos atreveríamos a señalar como autor de la misma a José Echamoro que por estas fechas era Maestro Mayor de la ciudad y también había realizado una remodelación importante en la Puerta de Córdoba de su ciudad natal de Carmona ${ }^{9}$. Comparando las fotografías de ambas puertas no dejan de ser sorprendentes sus coincidencias.

8. Este extremo lo confirma también otra fotografía realiada por A. Ciarán publicada por Luis Montoto, Op. cit.

9. Hernández Díaz, J., Snacho Corbacho, A. y Collantes de Terán, F. «Catálogo Arqueológico y Artístico de la Provincia de Sevilla». Tomo I. Sevilla, 1939. 


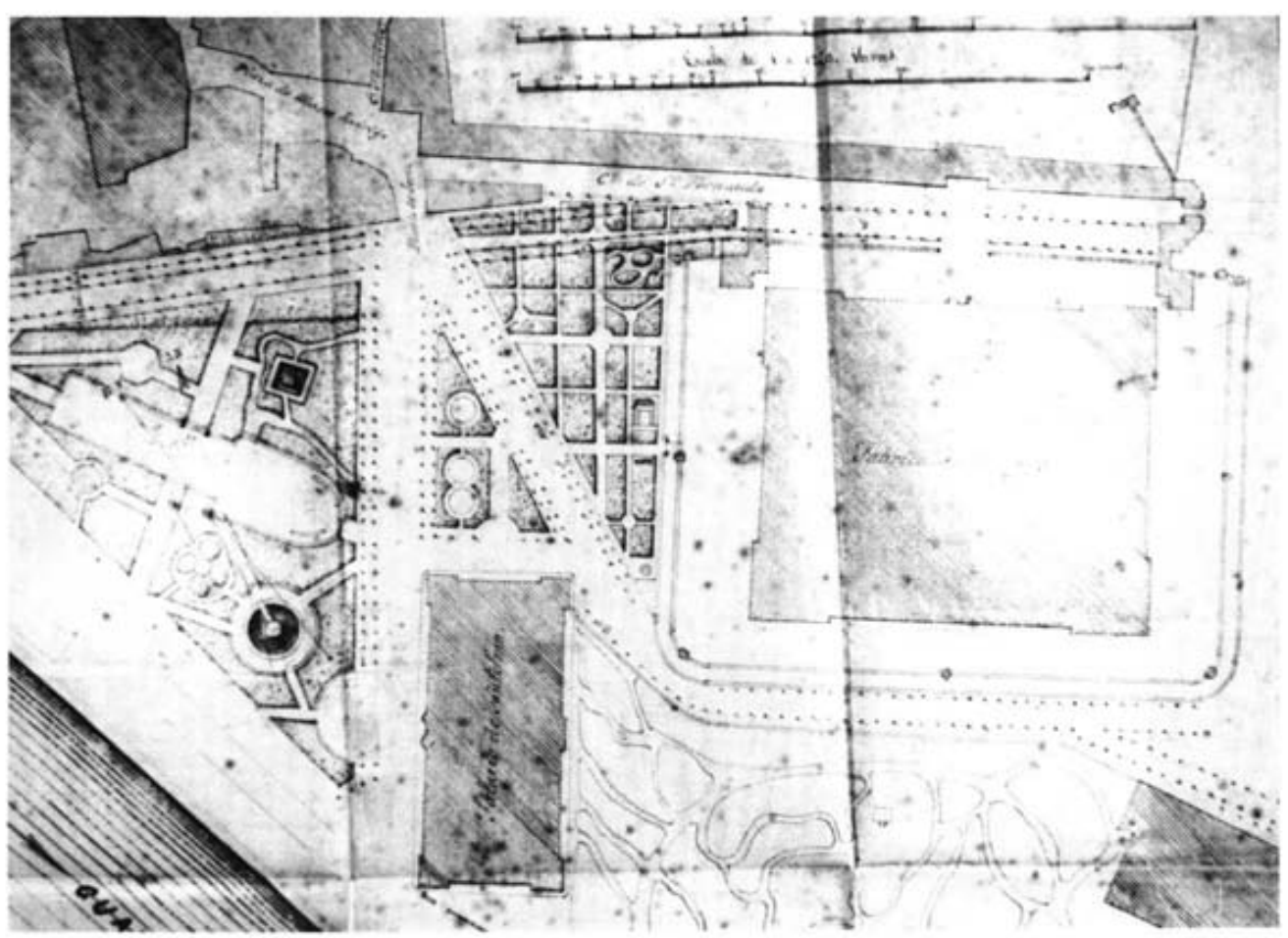




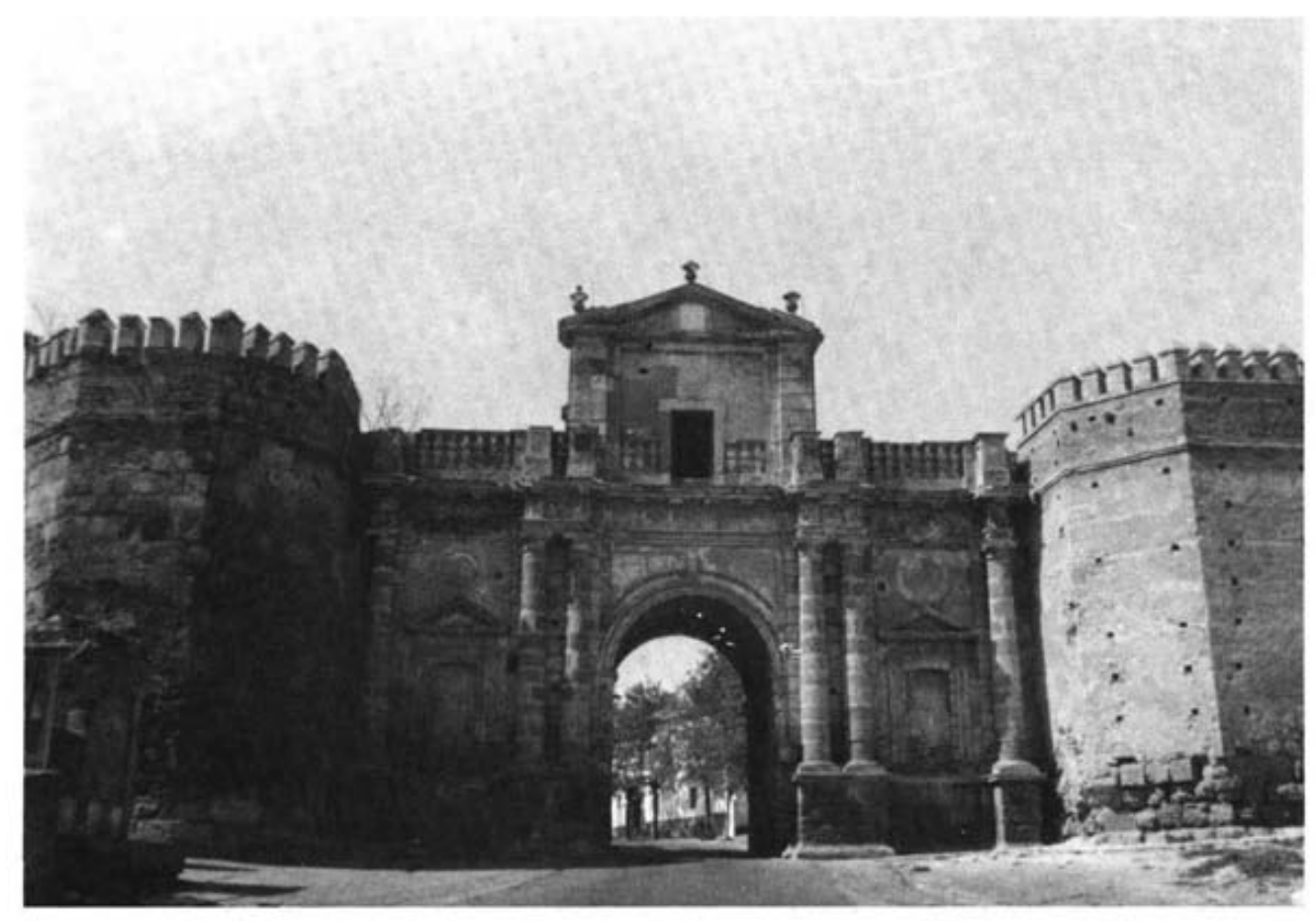

Fig. 2

Puerta de Córdoba en Carmona. 


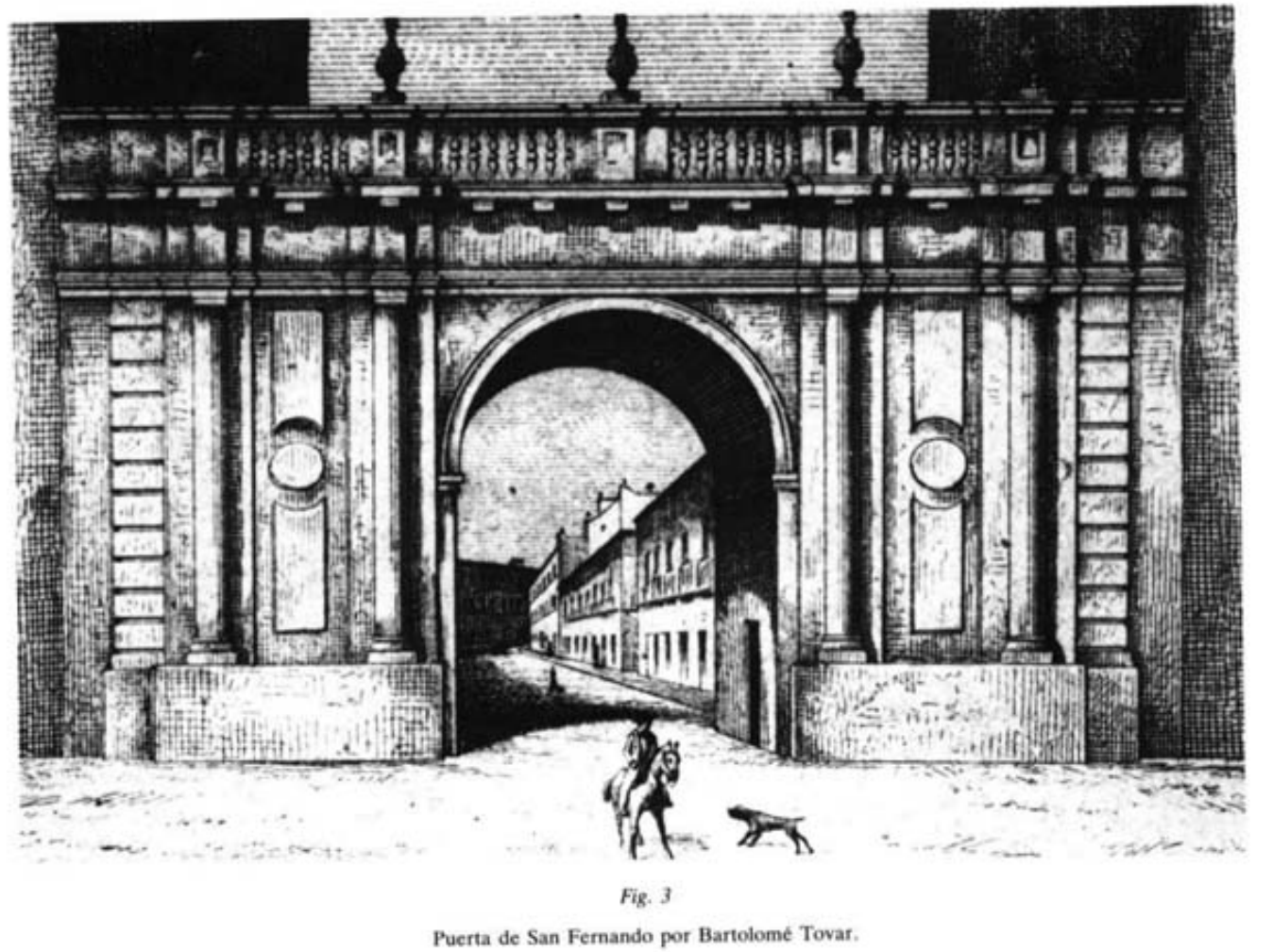




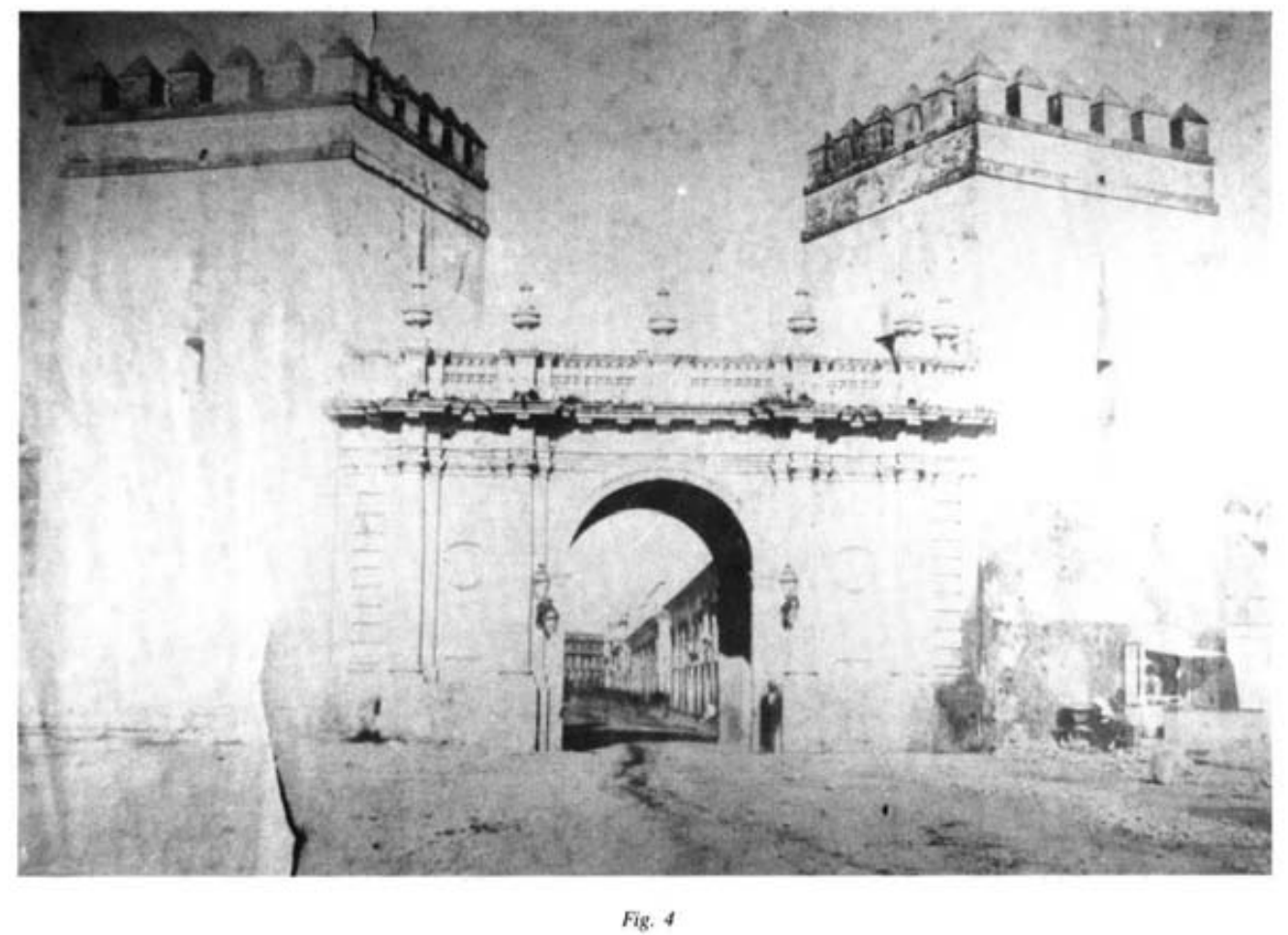

Puerta de San Fernando hacia 1868. 


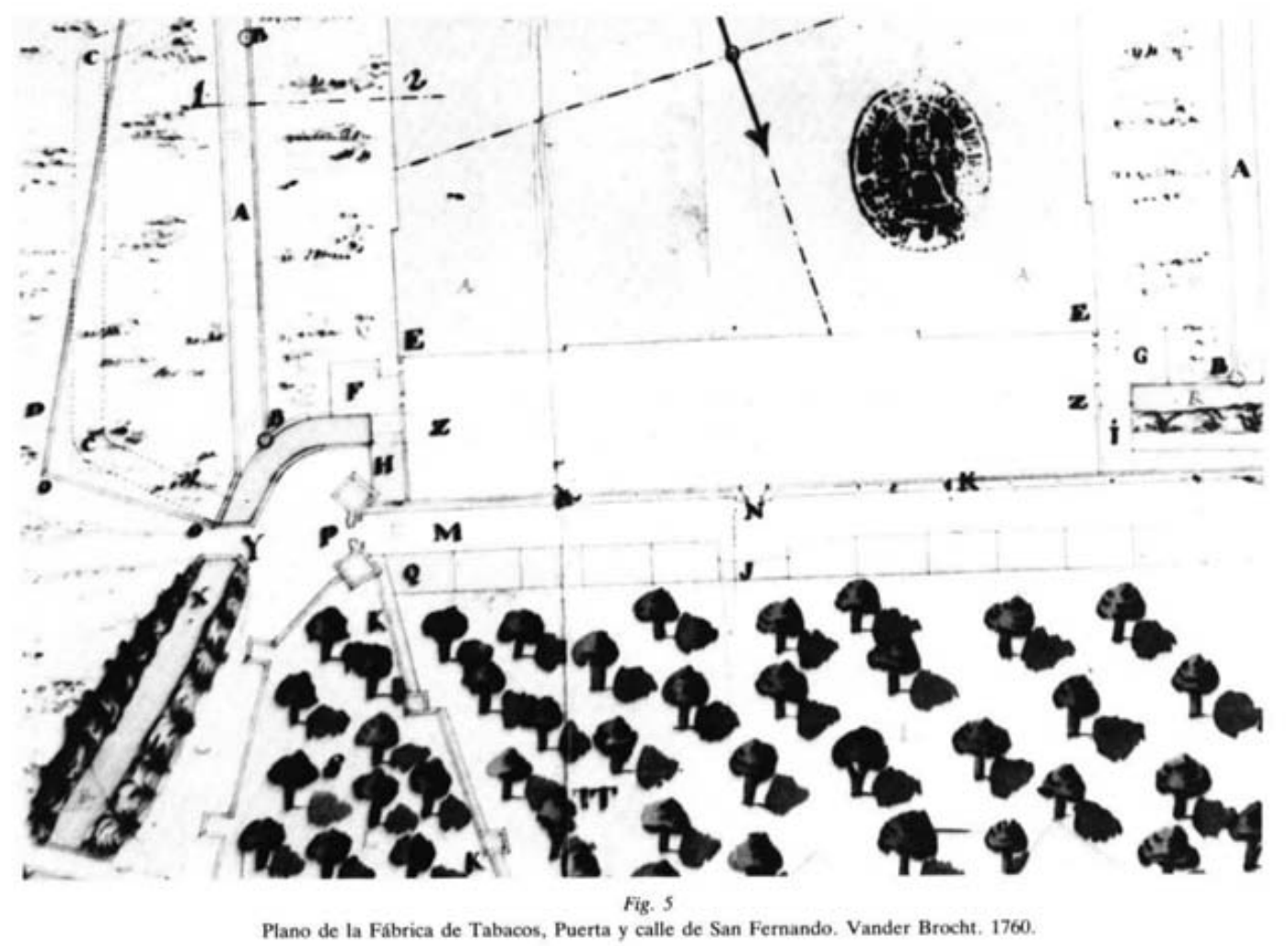

